BLocks 1.4

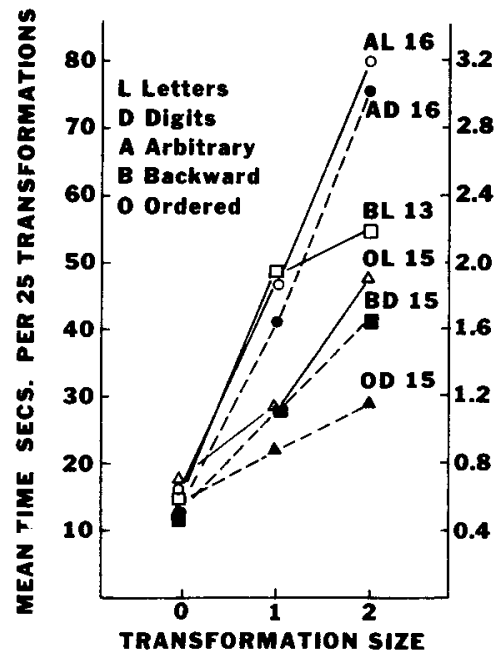

Fig. 1. Response times as a function of transformation size and sequence. The left ordinate indicates time to complete a 25-item list; the right ordinate is a conversion to time per item obtained by dividing by 25 . The number in parentheses beside each function indicates the number of monotonic relations obtained out of a possible 16.

letters. The exception was Condition A2, in which only 10 of the 16 comparisons revealed more rapid processing for digits.

Examination of Table 1 shows that letter frequences bear little relationship to mean processing times. To take but one instance, zero-order transitions show the lowest mean frequency, but the zero-unit transformation was performed the most rapidly.

Error rates for the various conditions were extremely low, even though the instructions were designed to encourage a moderate number of errors. The highest error rate was $1.8 \%$ (Condition $\mathrm{AL} 2$ ), and the lowest error rate was $0.0 \%$ (several of the zero transformation conditions).

There were practice effects over blocks. The best way to describe these effects is in terms of processing rates. For each block, the reciprocals of the slopes of functions similar to those in Fig. 1 would give a measure of items per second searched through memory. For the slowest condition, $\mathrm{AL}$, the search rate (reciprocal) varied from about one-half to one item per second from Block 1 to Block 4. In the most rapid condition, OD, search rates varied from about three to four items per second from Block 1 to Block 4.

\section{DISCUSSION}

Clearly the nature of the sequence is important. This is shown in two ways. First, for the larger transformations, if letters and digits are considered separately, processing rates show an increase corresponding to the sequences $A, B$, and $O$, respectively. Second for a given kind of sequence the stimulus material is important; search rates are more rapid for digits than for letters. The reasons for these effects are not clear-cut, since storage and retrieval demands required by the six sequences are fairly minimal and error rates are very low.

It is possible that digits are processed more rapidly than letters because of a short-circuiting between stimulus and response items, i.e., a nonserial process in which stimulus-response pairings could bypass intervening items in the sequence. However, a nonserial process ought to produce functions that are not strictly monotonic with respect to size of transformation; this rarely occurred. Also, the differences in times for zero- and one-unit transformations cannot be accounted for on the basis of short-circuiting. Finally, high-frequency letter transitions, as shown in Table 1, might be expected to aid short-circuiting; but there is no obvious frequency relation to the results obtained, a finding consistent with the earlier study (Weber et al, 1968) which used different stimulus letters.

The present results differ substantially from those of Sternberg (1967), who obtained search rates of 25-30 items per second in a recognition memory task. The present rates (one-half to four items per second) are consistent with those of the prior study (Weber et al, 1968). Taken together with the earlier study and introspective reports, the findings of approximately linear functions and low search rates suggest an internal speech process (Weber \& Bach, in press). The speech process would operate such that there is direct access to a sequence item in the zero transformation conditions, but when initiating retrieval from memory for oneand two-unit transformations, $S$ enters the sequence at random (or some fixed arbitrary point) and begins generating items via implicit speech. He continues generating items in the sequence until the stimulus is reached, and an appropriate meter reading (size of transformation) beyond the stimulus shows up-at that time $S$ writes out the last item generated. A possible reason for generating items would be to transfer them to an immediate or operating memory (Brooks, 1968; Posner, 1967) where they could be metered. In an ordered sequence (or after an arbitrary sequence is well learned), generation would not begin at a random point. Direct generation, starting with the stimulus, would be possible, and metering could begin immediately.

\section{REFERENCES}

BROOKS, L. Operating memory for words in a sentence. Proceedings of the American Psychological Association, 1968, 23-24.

LANDAUER, T. Rate of implicit speech. Perceptual \& Motor Skills, 1962, 15, 646.

POSNER, M. Short-term memory systems in human information processing. Acta Psychologica, 1967, 27, 267-284.

STERNBERG, S. Two operations in character-recognition: Some evidence from reaction-time measurements. Perception \& Psychophysics, 1967, 2, 45-53.

UNDERWOOD, B., \& SCHULTZ, R. Meaningfulness and verbal learning. Philadelphia: Lippincott, 1960.

WEBER, R., \& BACH, M. Visual and speech imagery. British Journal of Psychology, in press. WEBER, R., CROSS, M., \& CARLTON, M. Searching circular sequences. Journal of Experimental Psychology, 1968, 78, 588-592. NOTES

1. This study received financial support from the Research Foundation, Oklahoma State University, Stillwater, Okla. 74074

2. An earlier version of this report was presented at the Psychonomic Society, St. Louis, 1968.

3. The transitions from "e" to "a" and from " 5 " to " 1 " are breaks in the normal letter or digit sequence. The effects of single sequence-break transitions such as these have been found to dissipate rapidly with practice (Weber et al, 1968). So as a first approximation, the circular lists may be considered as having homogeneous transitions between adjacent items.

\title{
The effect of partially irrelevant anchors on verbal conceptual thinking
}

\section{E. TRESSELT, New York University, New York, N.Y. 10003}

Three groups of 200 Ss each, a total of $600 \mathrm{Ss}$, were given lists of words to categorize as belonging to specific concepts. Group 1 had no anchoring words in their list; Group 2 had 10 anchoring words not pertinent to the category in question; and Group 3 had 10 anchoring words pertinent to the category in question. Analyses of variance showed significant differences between groups. It is suggested that irrelevant words may operate in two ways, as a generalized "strength of concept" and as "content" anchors. 
Table 1

Means (M), Standard Deviations (SD) of Words Checked in Experiments 1 and 2 for the Economic and Theoretical Concepts by Groups 1-3

\begin{tabular}{|c|c|c|c|c|}
\hline \multirow[t]{2}{*}{ Experiment 1} & \multicolumn{2}{|c|}{ Economic Concept Only } & \multicolumn{2}{|c|}{ All Six Concepts (Economic) } \\
\hline & M & SD & M & SD \\
\hline $\begin{array}{l}\text { Group } 1 \text { (control) } \\
\text { Group } 2 \\
\text { Group } 3\end{array}$ & $\begin{array}{l}29.20 \\
25.16 \\
21.72\end{array}$ & $\begin{array}{l}19.43 \\
23.10 \\
20.72\end{array}$ & $\begin{array}{l}22.14 \\
11.90 \\
13.20\end{array}$ & $\begin{array}{l}14.95 \\
17.13 \\
10.98\end{array}$ \\
\hline \multicolumn{5}{|l|}{ Experiment 2} \\
\hline $\begin{array}{l}\text { Group } 1 \\
\text { Group } 2 \\
\text { Group } 3 \\
\end{array}$ & $\begin{array}{l}\text { Theore } \\
34.60 \\
24.80 \\
20.84\end{array}$ & $\begin{array}{l}\text { Only } \\
16.43 \\
19.60 \\
17.74 \\
\end{array}$ & $\begin{array}{c}\text { All Six Cc } \\
21.86 \\
19.76 \\
21.22 \\
\end{array}$ & $\begin{array}{l}\text { oretical) } \\
18.93 \\
21.09 \\
16.44\end{array}$ \\
\hline
\end{tabular}

In recent years there has been much research and interest in concept formation and conceptual thinking as a fundamental cognitive process. While most of the work is centered around acquiring concepts, i.e., concept formation, other studies would seem to fall under the rubric of the use of concepts or concept utilization. The first situation involves learning how to categorize stimuli; the other situation involves selecting those stimuli which seem to belong to a given category already within the repetoire of the $\mathrm{S}$. This second task may or may not have a learning component, i.e., the $S$ may or may not be given feedback on whether he has behaved correctly.

Mayzner \& Tresselt (1955) published data to indicate that when an individual is asked to check words of a long list of words which he feels belongs to the concepts of $T$ (theoretical), E (economic), A (aesthetic), S (social), P (political), and R (religious) he will check more words for those concepts in which he scores high on the corresponding high value on the Allport-Vernon Lindzey Scale of Values test than for those concepts on which he scores low.

In further research (Mayzner \& Tresselt, 1958, 1959), they showed that Ss, given words which have been previously scaled and found to be low in frequency of inclusion in a particular concept, judged more such words as belonging to that concept than $S s$ who had been given instances of words of high frequency of inclusion before judging the low-scaled words. When the number of anchoring stimuli were systematically varied, the results indicated that 10 anchors per category maximized the effects over the range of 200 critical words (low-scaled words) used.

In the cited work, either all or no anchoring stimuli were presented. While it is logical to state that high-scaled, economic words, e.g., "expenditure," "sale," "cost," "wages," would set the S for strong belongingness words, the low-scaled words would not belong as easily, not only to the concept but also to the "strength of concept." Therefore, it was hypothesized that if Ss we re given 10 high-scaled words for TASPR, but none for E, they would check more words as belonging than if they had had no high-scaled words, but less words than if they had had specimen high-scaled words.

\section{PROCEDURE}

Experiment 1

There were three groups of $50 \mathrm{Ss}$ each, a total $\mathrm{N}$ of 150 . Each $\mathrm{S}$ was presented with a list of words and asked to check the words as belonging to none, $1,2,3,4,5$, or 6 of the concepts of TEASPR. Group 1 (control) was given a list of 100 words which had been previously scaled for frequency of inclusion and were found to have been checked only $0 \%$ to $20 \%$ of the time. These words included such words as "second, blow, loud, coma, rain, mirror, jump, sink, echo, the," and so forth. Group 2 was given a list of 150 words. The first 50 words (which were not set apart in the lists) consisted of a random presentation of words previously scaled as having a high frequency of inclusion in the single concepts TASPR (10 each) at the $80-100 \%$ level of inclusion. The concept "economic" was not included; hence, there were 50 anchoring words followed directly by the 100 words of the control group. Group 3 was given 160 words, 10 words of the high-inclusion value for each of the six concepts TEASPR followed by the 100 test words.

Another three groups of 50 Ss (total $N=150$ ) were given exactly the same stimuli but were asked only to check for the

\section{Experiment 2}

Six groups of Ss (total N = 300) repeated the first experiment, but Group 2 was given 150 words in which 10 anchoring stimuli for the theoretical scale were missing, replaced by economic words. Their task was the check for all six categories. The second half of the experiment was repeated with the Ss only asked to check whether or not the words belonged to the concept "theoretical."

\section{RESULTS}

Table 1 presents the means $(M)$ and standard deviations (SD) for the number of category "economic." words included in the critical concepts. (The standard deviations are large relative to the means because the distributions were skewed with ranges sometimes spreading from 0-100.)

The analyses of variance for each experiment/showed a significant difference between groups (Experiment 1, F = 6.81; Experiment 2, F = 4.41).

\section{DISCUSSION}

Inspection of the results of checking the concepts of economic alone and theoretical alone show clear support for the hypothesis. The greatest number of words checked 29.20 and 34.60 occur in the control group where there are no anchoring stimuli. The results also support previous research (Mayzner \& Tresselt, 1958, 1959). Having anchoring stimuli decreases the number of words belonging to the concept, which also has been found previously. However, it now becomes clear that having anchors not relevant to the concept in question seems to act upon the number of words checked, and these anchors seemingly are generalized to the concept being judged so that Group 2 means are intermediate between Groups 1 and 3.

Inspection of the data where all six concepts were judged shows the greatest number of words being checked by the control group, but the results are not in the same order as with the single-concept situation for Groups 2 and 3 . It seems plausible to assume that the $S$ is more aware of the relation of all six concepts to the 100 test words and that two different concepts may have been formed, one having to do with the content of the concept and the other having to do with the strength of the concept. That is to say, whether or not economic words were present in the anchoring series was not important. Since the concepts were being represented by strong words, then the checking behavior was essentially similar to the presence of the anchor, Groups 2 and 3. It can be argued that the "strength of anchor" generalized to such an extent that the two groups performed similarly when all the concepts were being considered by the $S$.

\section{REFERENCES}

MAYZNER, M. S., \& TRESSELT, M. E. Concept span as a composite function of personal values, anxiety and rigidity. Journal of Personality, $1955,24,20-33$.

MAYZNER, M. S., \& TRESSELT, M. E. Shifts in connotative meaning of words as a function of previous restrictive experience. Journal of Experimental Psychology, 1958, 55, 200-205. MAYZNER, M. S., \& TRESSELT, M. E. Shifts in connotative meaning of words as a function of varying amounts of previous restrictive experience. Journal of Psychology, 1959, 47, 107-116. 